\title{
O suicídio Tikúna no Alto Solimões: uma expressão de conflitos
}

\author{
Suicide among the Tikúna on the Upper \\ Solimões River: an expression of conflicts
}

Regina M. de Carvalho Erthal 1

\footnotetext{
1 Divisão de Antropologia, Museu Amazônico, Universidade da Amazônia, R. Ramos Ferreira 1036, Manaus, $A M$ 69010-120, Brasil.
}

\begin{abstract}
This study focuses on suicide among the Tikúna Indians on the Upper Solimões River in the Brazilian Amazonia. The very nature of the object requires an interdisciplinary approach. The ethnography is concerned with capturing links among suicides occurring over the last decade, in the process of confrontation between different factions or groups that express, in the present, an older historical context, the mechanisms of conflict characterizing the ancient malocas, or indigenous lodges. At the very base of such confrontations lies the abandonment inflicted on this population, especially the bankruptcy of the health care model proposed for the Upper Solimões area.
\end{abstract}

Key words Suicide; Health; Tikúna; South American Indians

Resumo O objetivo deste trabalho é buscar um entendimento a respeito da ocorrência de suicídios entre os índios Tikúna do Alto Solimões (Amazonas), um objeto de difícil aproximação e que aponta para a necessidade de abordagem interdisciplinar. A etnografia realizada preocupou-se em captar a vinculação entre os eventos de suicídio da última década com a exacerbação dos confrontos entre diferentes grupos faccionais que atualizam, em outro contexto histórico, os mecanismos de resolução de conflitos próprios das antigas malocas. Na base desses confrontos está o abandono a que tal população tem sido submetida pelos órgãos responsáveis pela definição e implementação das políticas públicas para as populações indígenas, com especial destaque para a falência do modelo de assistência proposto para a área do Alto Solimões.

Palavras-chave Suicídio; Saúde; Tikúna; Índios Sul-Americanos 


\section{Introdução}

A partir de 1994, notícias a respeito da ocorrência de epidemia de suicídio entre os índios do Alto Solimões passaram a ser veiculadas regionalmente, ganhando destaque, logo a seguir, nos meios de comunicação que contam com abrangência nacional. As notícias acerca do suicídio entre os Tikúna divulgavam que adolescentes - preponderantemente, na faixa etária de 10 a 15 anos - estariam se matando por causa das regras de casamento tradicionais, já defasadas da realidade 'moderna' dos jovens índios. Tais regras ter-se-iam tornado obsoletas ("problemas de nação"), limitando a escolha dos jovens, os quais, diante da proibição de realização de seu desejo amoroso, procuravam a morte ou por enforcamento ou pela ingestão de veneno.

A ausência de registros sistemáticos relativos a doenças e agravos à saúde para o conjunto da população Tikúna determinou maiores cuidados no que concernia às notícias que enfocavam a ocorrência da epidemia no Alto Solimões, cujo número de casos aumentou entre os anos de 1993/94. A epidemia teria sido identificada principalmente em duas grandes comunidade, cuja localização favoreceria intenso contato com a sociedade regional - Belém do Solimões e Umariaçú -, bem como nas pequenas comunidades do igarapé do Belém, sob a jurisdição do Posto Indígena Belém do Solimões.

Como parte da caracterização do suicídio Tikúna efetuada pelos diversos agentes do contato que atuavam na área, o consumo de bebidas alcoólicas e um suposto aumento dos diversos tipos de violência encaminhavam as 'análises' para a constatação de perda dos padrões culturais e a um processo desestruturante da integração na sociedade nacional. Essa caracterização do senso comum, que não pode ser vista como neutra e isenta, tornou-se o ponto de partida da pesquisa.

Procurou-se entender o suicídio Tikúna através de um referencial analítico que encaminhasse à superação dos esquemas mais tradicionais que fundamentam a sua argumentação na suposição de "via única" de mudança para as sociedades indígenas. Deve-se considerar, então, a possibilidade de trabalhar com os conflitos que perpassam as comunidades no que tange às escolhas de desenvolvimento $\mathrm{e}$ aos modos específicos de relacionamento com a sociedade nacional (Barth, 1967; Gluckman, 1968; Oliveira, 1996; Oliveira Filho, 1988; Wachtel, 1976). No plano interno, as sociedades indígenas devem ser percebidas não mais como constituídas de interesses homogêneos e com projeto político único. A sociedade Tikúna, tradicionalmente transpassada por um faccionalismo que se apoia na organização de metades e clãs, vem incorporando, em diferentes momentos de seu processo de contato, outros recortes e fragmentações, para os quais busca acúmulo de forças nos esquemas de alianças possíveis entre os diferentes grupos e/ou a partir de seus suportes externos.

Para as atuais gerações de jovens Tikúna, ao lado dos conflitos e processos de estresse oriundos das mudanças específicas inerentes aos diferentes ciclos de vida biológica, colocam-se outros fatores de instabilidade, definidos a partir da exigência de sua participação ativa em um processo de mudança social acelerado e em busca da construção de cenários mais vantajosos (Young, 1982). A proposta, no entanto, não é a de estabelecer vias de escolhas ou padrões de comportamento que se traduzam em termos de dualidade entre tribal/não tribal, "cabo do terçado/estudo", já que o estabelecimento dessas dicotomias certamente desemboca no reducionismo dos conflitos internos do grupo a uma oposição entre os que desejam integrar-se à sociedade nacional e os que pretendem a manutenção das tradições tribais.

Neste sentido, a apresentação de uma interpretação Tikúna para os eventos de suicídio não deve ser vista apenas como tentativa de identificação dos traços culturais tradicionais, para que se possa opor à argumentação que tende a identificar os grupos com intenso contato com a sociedade nacional dentro de um processo inevitável de anomia, resultado de suas dificuldades de integração nessa mesma sociedade. Não se pretende ainda, mostrar a existência de "cultura híbrida", resultado da mistura de elementos das culturas originais em contato.

Dando destaque à possibilidade de ler através dos eventos de suicídio e violência a expressão de encadeamento entre conflitos faccionais atualizados pela sociedade Tikúna em diferentes "situações históricas" (Oliveira Filho, 1988), interessa indicar o modo pelo qual os agentes sociais atribuem sentido a determinado acontecimento. Mais ainda, é necessário apontar para a possibilidade de entendimento da complexificação das ações de cada ator étnico, cada qual operando a partir de uma lógica cultural específica, referidas à extensa rede de relações que ultrapassa o nível local (Gluckman, 1968), mas empenhado no processo de especular e traduzir, para seus próprios códigos, outros modos de agir e pensar. 


\section{O povo Tikúna do Alto Solimões}

De acordo com as avaliações elaboradas pelas lideranças Tikúna, sua população pode ser considerada a maior população indígena no Brasil, contando cerca de 26.000 indivíduos. Situados na região da fronteira do Brasil com a Colômbia e o Peru, a população total foi estimada em 31.700 indivíduos (ISA, 1996).

O processo histórico de ocupação e exploração do território Tikúna fez com que houvesse movimentos de deslocamento e de concentração populacional a partir do século XVIII. No final do século XIX, a expansão da exploração da seringa no Alto Solimões fez-se segundo um processo de dissolução das malocas tradicionais, tendo havido a transferência dos indígenas para as margens do Solimões em atenção aos interesses da empresa seringalista. Mais recentemente, a partir da década de 70, os deslocamentos foram acentuados em um processo de "urbanização" movido pela busca dos aldeamentos equipados com escolas e postos de saúde, bem como, paralelamente, pelo chamado do Irmão José (brasileiro), quem, dizendo-se dotado de "visão celestial divina", passou a colocar cruzes nos aldeamentos, prometendo a salvação para aqueles que ali se reunissem e cumprissem os mandamentos da "cruzada apostólica” (Oliveira, 1978; Oliveira Filho, 1977).

Os Tikúna do Alto Solimões estão atualmente divididos em mais de 100 comunidades, que são distribuídas desde a calha principal do Rio Solimões até o alto de seus igarapés tributários, e estão referenciadas a oito diferentes municípios. Em alguns deles, a população indígena constitui mais da metade da população rural total. Sua língua isolada é dominada apenas por membros dessa etnia e tem sido sistematicamente defendida pelo uso cotidiano nas aldeias - em especial, pelas mulheres junto às crianças. A organização social dos Tikúna supõe a sua divisão em clãs, agrupados em duas metades exogâmicas que não são nominadas. Atualmente, esses grupos são referidos, em português, como 'nações', as quais adotam os nomes de árvores, animais terrestres e insetos (metade A) e aves (metade B). Para Oliveira Filho (1988), o critério de distintividade estaria na separação que os indígenas fazem entre $n a$ ções de pena e nações sem pena. Mesmo sem referência direta às metades no cotidiano, a sua importância está ligada ao fato de designarem os casamentos permitidos. Os indivíduos buscam seus parceiros na metade oposta à sua, e o pertencimento dos filhos a uma nação faz-se por linha paterna. O desrespeito à exogamia, se cometido casualmente, pode ser punido com censura pública sem que haja exclusão definitiva dos indivíduos das atividades sociais. No entanto, as ligações incestuosas prolongadas causam "horror e repugnância" aos parentes e podem resultar em "tragédias de sangue" com acusações públicas e mortes violentas, que são vistas, no entanto, como restauradoras do estado de normalidade (Nimuendajú, 1952:62). Além do incesto, outros dois crimes - o infanticídio e a feitiçaria - são considerados de extrema gravidade, já que não prejudicam apenas um indivíduo, mas à comunidade como um todo.

\section{A teoria etiológica Tikúna}

As explicações dadas pelos Tikúna para seus processos de adoecimento e morte fazem referência, de forma recorrente, a uma explicação do tipo xamânica, mostrando a sua importância no pensamento e na vida cotidiana desse povo enquanto sistema de representações, visão e reflexão acerca do mundo. A relevância do xamanismo em diversas comunidades indígenas que pertencem ao mesmo conjunto de nações que dominam as áreas de fronteira entre Brasil, Peru e Colômbia tem sido demonstrada por diversos autores. Chama a atenção, tanto na literatura concernente aos Yágua classificados como pertencentes a um modelo de "xamanismo de ataque", da mesma maneira que os Tikúna (Chaumeil, 1991) - quanto naquela relativa aos Siona (Langdon, 1994), a interligação de noções centrais como doença/ morte/vingança é interpretada em relação ao xamanismo e usada, em seu conjunto, como justificativa para a ocorrência de hostilidades entre grupos locais.

A concepção que os Tikúna têm da doença permite a especulação a respeito das causas naturais e da intervenção de agentes externos - enviada pelos pajés -, que podem ser entendidas enquanto níveis diferenciados de causalidade não mutuamente excludentes. Os males com origem externa e sobrenatural podem ser imputados ou à quebra das regras de evitação (alimentar, sexual etc.) estabelecidas para cada período da vida do indivíduo, ou à interferência de malefício causado pela "inveja” e/ou pela "raiva" de outrem. O comportamento dos membros da família interfere na saúde do conjunto de seus membros, da mesma forma que alguns ensinamentos ministrados no decorrer do desenvolvimento da criança e do jovem têm o sentido de colaborar na prevenção de doenças, já que visam a criar indivíduos "fortes" e com o "corpo fechado" ante às diversas possibilidades de ataque do mundo invisível. 
Reunindo as tarefas de curar, adoecer e matar, o pajé Tikúna sempre exerceu a função de principal repositório do conhecimento das ervas - dos medicamentos do mato -, que podem responder a uma gama razoável das doenças. No entanto, a noção de eficácia terapêutica que, para os indígenas, recobre áreas mais amplas do que a simples remissão de sintomas objetivada pela medicina ocidental - permite o uso pragmático dos serviços médicos colocados a sua disposição, na medida em que estes possam oferecer melhoria rápida dos sintomas, sem existir, nesse uso, a negação do próprio sistema de tratamento.

As doenças de criança são atribuídas, em geral, à quebra de restrições alimentares ou a atitudes negligentes dos pais em relação a uma série de cuidados que, se não forem observados, "vingam" a criança. Neste caso, elas podem ser levadas a um curador cujo trabalho é feito pela defumação da criança e mediante a retirada da parte do animal (esporão do surubim ingerido pela mãe) ou objeto (se o pai tocar em instrumento de ferro) que "vingou" a criança. As doenças prolongadas, em crianças que não reagem aos chás ou mesmo aos remédios do posto ou hospital, são diagnosticadas como resultado da perda ou "afastamento" da alma. Nesta situação, a cura é realizada mediante a busca da alma - que deve ser negociada pelo curador com o espírito maligno que a roubou - e pela sua reintrodução na criança.

Nos casos de adoecimento em que a dor localizada permite que se determine o lugar do impacto do mal, a introdução de corpo estranho no organismo do paciente fica evidente e o diagnóstico é de "feitiçaria". Um pajé deverá ser procurado para retirar a "xunta”, descobrir o "feiticeiro" que está mandando "sua porcaria" e negociar o fim da querela com este. Tal busca pela 'causa última' das doenças realizada junto aos pajés está associada usualmente à intensidade, duração e resistência a outros tratamentos, o que envolve a existência de outros fatores envolvidos no evento (disputas faccionais). A “cura" parece abranger igualmente a participação da família, que, na verdade, é atingida como um todo. O processo de conflito que desencadeia agressão pode estar indicando que o objeto do feitiço não é apenas o indivíduo, mas uma unidade social mais ampla. No adoecimento por "feitiço" existe sempre a necessidade de busca da causa última e da negociação do final do conflito. No caso de morte súbita ou suicídio, pode ou não haver o recurso ao pajé para a descoberta do autor do "feitiço", mas sempre será feita a avaliação acerca da autoria e das circunstâncias e atribuição de culpa. Con- tudo, essas apreciações não são colocadas de modo evidente, pois indicam disputas que, muitas vezes, extrapolam o âmbito local ou familiar. Se, por um lado, a doença pode ser atribuída a fatores naturais e, portanto, ser tratada segundo uma teoria do corpo, da natureza e da nutrição, por outro, a morte prematura ou súbita sempre será imputada à interferência de espíritos malignos enviados por feiticeiros. Neste sentido, independente da diversidade dos eventos de doença com que se tenha deparado no trabalho de campo, é interessante notar e ressaltar a estreita relação que os Tikúna estabelecem entre o adoecimento e a morte como eventos de conflito que têm, como decorrência, o desencadeamento de outras formas de sofrimento, agressão e morte, que são, em última instância, a expressão de disputas dentro de cenários historicamente datados, fruto de relações sociais concretas.

Essas observações são especialmente pertinentes para o quadro de mortalidade por causas externas na sociedade Tikúna, na qual é possível supor que a notificação de afogamentos, quedas e mortes súbitas possa estar ocultando a ocorrência de assassinatos levados a cabo por feiticeiros (em geral, o daqueles mortos por afogamento), particularmente, em comunidades com marcadas cisões de cunho religioso, nas quais esses eventos não são referidos nem computados nas estatísticas oficiais, as quais, por sua vez, apontam para a existência de graves disputas faccionais que possibilitariam o desencadear da ocorrência de suicídios. A criação de meios de avaliação de fenômenos que passam normalmente despercebidos pelos métodos clássicos de medida de morbimortalidade (já que baseados apenas no diagnóstico médico), ocasionaria "alargamento” do campo da saúde com a incorporação de outras "fontes idôneas de julgamento" (Goldberg, 1990:124).

No caso da área Tikúna, a ausência crônica de profissionais de saúde - notadamente, a partir de 1995 - e a notificação realizada pelos Agentes Indígenas de Saúde (AIS) - orientados para anotar apenas mortes de causas consideradas de identificação óbvia (afogamentos, suicídios, quedas etc.- ocasionaram a anotação de apenas dois grandes grupos de causas: morte por causa externa e SAM (Sem Assistência Médica). Acrescente-se, a esses fatores, a dificuldade, comum às instituições governamentais de assistência à saúde, de reconhecer e incorporar saberes e entendimentos diferenciados das populações indígenas a respeito de seus processos de adoecimento e morte. Uma qualificação sistemática das mortes ocorridas na 
área indígena Tikúna nos últimos anos - despersonalizadas e desqualificadas sob a rubrica SAM. - poderia apontar para a vinculação entre os processos de adoecimento e os prováveis desdobramentos em termos de acusações de enfeitiçamentos, contrafeitiços, mortes violentas, suicídios, tal como para o que Taussig (1993) denominou "relações sociais incrustadas na feitiçaria”.

\section{Descrição do evento: características gerais}

O levantamento de dados acerca dos suicídios indígenas no Alto Solimões foi efetuado em diferentes momentos, entre 1994 e 1996, com períodos diversos de permanência nas comunidades, privilegiando aí a coleta de dados qualitativos (Erthal, 1996, 1998; Erthal et al., 1994). Um trabalho de campo mais intenso foi realizado na comunidade de Belém do Solimões, com incursões junto às comunidades de Umariaçu, Filadélfia, Vendaval e Betânia. É importante destacar que, desde o final da década de 80, a autora fez parte do quadro de assessores do Conselho Geral da Tribo Tikúna (CGTT ONG indígena constituída pelos "capitães" das comunidades), quando participava da discussão de projetos na área da saúde e, desse modo, era identificada pela maioria de meus informantes. Participou ainda de reuniões diversas que permitiram o contato com representantes de comunidades distantes, assim como a observação de situações de disputas/alianças faccionais, essenciais ao entendimento das diversas conjunturas políticas que se apresentaram no decorrer do período de campo. Os dados quantitativos de morbimortalidade foram igualmente levantados nos períodos de campo, devendo ser vistos como produto da conjuntura de disputas entre a Fundação Nacional do Índio (FUNAI) e a Fundação Nacional de Saúde (FNS) pelo controle da saúde do índio (Verani, 1996), o que se refletia em baixa qualidade, tal como nas dificuldades interpostas à disponibilização para a pesquisa.

Na Delegacia Regional da FUNAI em Tabatinga/AM, dois tipos de registros de dados de mortalidade puderam ser encontrados, diferenciados pelas origens das informações que os compõem. O "Boletim Bimestral de Notificação de Óbitos” tem sido elaborado, na prática, a partir de dados relativos aos óbitos anotados pelos AIS e repassados pela FNS à FUNAI, bem como das anotações de óbitos ocorridos no Hospital da Guarnição de Tabatinga, restringindo as informações à área dos municí- pios de Tabatinga e Benjamin Constant, os de maior atuação da FNS. As tentativas de levantamento de informação acerca da ocorrência de mortes na área Tikúna como um todo mostraram-se infrutíferas - tanto na FNS quanto na FUNAI - em decorrência de diversas mudanças na coordenação dos trabalhos de assistência na área durante o período considerado. O segundo tipo de registro reúne, sob a rubrica "Relação dos Acontecimentos Negativos das Comunidades Indígenas”, todas as notificações oficiais oriundas dos Postos Indígenas, poder judiciário, polícia local, ou denúncias dos índios, relativas à ocorrência de eventos violentos que tenham redundando ou não em morte (ameaças de morte, invasão, tentativa de assassinato, estupro, assassinato coletivo promovido por pajé, afogamentos, suicídios ou tentativas). Esses dados foram encontrados na forma de Relatório Anual para o ano de 1993, ou dispersos no arquivo da Delegacia Regional da FUNAI de Tabatinga para os anos seguintes.

Os dados das comunidades pertencentes ao PI Belém do Solimões foram ampliados com as anotações do "Livro de Registro de Óbitos", realizadas pelo Chefe de Posto da FUNAI, através das quais foram levantadas as ocorrências de suicídio nas comunidades deste Posto Indígena, a partir de 1990. Os casos de suicídio para o ano de 1997 foram anotados pela enfermeira da FNS, responsável pelo Programa de Imunização das Comunidades Tikúna/TBT, e ampliados posteriormente pela coleta de dados junto ao AIS de Belém do Solimões.

Uma busca nos fichários da Equipe de Saúde do Índio do Hospital de Benjamin Constant - também ponto de referência para o encaminhamento da produção dos AIS - não se mostrou produtiva, uma vez que os dados de suicídio são registrados de modo irregular, como as anotações de mortalidade em geral, e sob um recorte de faixa etária tão amplo (<1ano; 1 a 4; 5 a 14; 15 a 58 anos) que impossibilita sua comparação com os dados produzidos pelas demais fontes.

Os dados de suicídio registrados pela FNS e FUNAI tomam por base uma população de 21.792 indivíduos - anotada pelos censos da FNS, de 1993 a 1996 -, cobrindo 6 dos 8 Municípios do Alto Solimões com presença de população Tikúna. É importante ressaltar, porém, que a avaliação feita pelo Instituto Sócio-Ambiental a partir de notícias de pesquisadores que trabalhavam em área, indicava, já em 1994, uma população de 23.000 indivíduos no Alto Solimões (ISA, 1996).

Os 57 suicídios anotados para o período de 1990 a 1997 referem-se principalmente aos Mu- 
nicípios de Benjamin Constant, Tabatinga e, de forma menos significativa, ao de São Paulo de Olivença. Para os municípios de Amaturá, Santo Antônio do Iça e Tonantins, onde a presença indígena é expressiva, não existem dados que permitam avaliação real da existência e magnitude do evento.

Deve-se reforçar essas ressalvas, já que, em um primeiro momento, os dados coletados evidenciaram predominância de suicídios nas comunidades sob a jurisdição do PI Belém do Solimões, que contribuiu com $61.4 \%$ do total de óbitos por essa causa, fazendo crer que as indicações apresentadas inicialmente pelas instituições locais estivessem corretas. No entanto, levando em conta as diversas origens das tentativas de suicídio, as referências concernentes a ocorrências de suicídios em 1994 na comunidade de Campo Alegre (Macedo, 1996) e as informações incompletas relativas a eventos em Betânia e a outras comunidades foi possível perceber uma distribuição divergente daquela desenhada originalmente pelos dados oficiais.

Há que distinguir, ainda, dentro da área de abrangência do PI Belém do Solimões, a situação específica das comunidades localizadas na direção do alto do igarapé do Belém - mais isoladas e com populações que variam de 50 a 208 indivíduos - daquelas comunidades "da beira". Os "índios do igarapé” ainda hoje são vistos como "os do centro", que preservam a organização tradicional, suas festas rituais, cujos pajés são poderosos, mas, ao mesmo tempo, permanecem longe dos benefícios da "civilização", encontrados na "cidade" de Belém do Solimões, situada à beira do grande rio. Os dados recolhidos, no entanto, indicaram que as comunidades "do centro" contribuíram com $28 \%$ do total de casos de suicídios entre 1990 e 1997, tal como com $45,7 \%$ dos casos ocorridos dentro da jurisdição do PI Belém do Solimões. Esses números serão significativos se pensados em relação à ocorrência concentrada de alguns períodos (1994), quando as três menores comunidades - Nova Jutaí (pop.: 50), Piranha (pop.: 78) e São Joaquim (pop.: 96) - contribuíram com 53,8\% dos casos. Apesar de não se contar com intervalo de tempo que permita maior acúmulo de informações, a distribuição do evento através de 5 anos, a partir de 1993 quando a FNS iniciou a organização de suas estatísticas de saúde - parece apontar para certa regularidade, com média em torno de 10 suicídios/ano (Tabela 1).

Os dados agrupados na Tabela 1 revelam predominância clara de indivíduos do sexo masculino tanto para suicídios exitosos $(73,6 \%)$ quanto para as tentativas $(77,7 \%)$. Com relação aos meios utilizados nos suicídios e tentativas tem-se que: 1) ambos os sexos utilizaram predominantemente a forca tanto para suicídios $(64,9 \%)$ como para tentativas $(87,5 \%) ; 2)$ do total de suicídios masculinos, $69 \%$ foram executados na forca; 3) para os indivíduos que empregaram o timbó (veneno), a maioria também foi de homens (68\%); 4) do total de suicídios de mulheres, $53,3 \%$ utilizou a forca e $33,3 \%$ do timbó; 5) houve apenas um suicídio com arma de fogo e um envenenamento por hipoclorito de sódio.

Colocando em foco os dados de suicídio referentes às aldeias de Piranha (pop.: 78) e Belém do Solimões (pop.: 2257) - inter-relacionadas por laços de parentesco, mas com características bastante distintas - pôde-se verificar dois padrões diversos de suicídio no que diz respeito à faixa etária de maior incidência e ao meio utilizado para a realização do ato. Para a comunidade de Belém do Solimões registrouse, de 1990 a 1997, a ocorrência de 19 suicídios - majoritariamente, entre indivíduos do sexo masculino $(84,2 \%)$-, com $57,8 \%$ no grupo etário de 16-18 anos e executado quase que totalmente por forca, pois somente dois indivíduos recorreram ao timbó. Em Piranha houve 10 suicídios - seis masculinos e quatro femininos -, dos quais apenas dois realizados por forca, parecendo procedente a afirmativa de que o uso do cipó venenoso (timbó) está relacionado muito mais ao acesso que se pode ter a ele (na mata) do que a uso vinculado a questões de gênero. Comparando a incidência dos suicídios por faixa etária na comunidade de Piranha com a que ocorre para a população total e para a população de Belém do Solimões, pode-se perceber importante mudança, já que a maior parte dos suicídios em Piranha se dá entre indivíduos entre 19 e 25 anos.

A análise de um dado importante como a distribuição dos eventos de suicídio e das tentativas pelos diferentes grupos de idade pode beneficiar-se sobremaneira de algumas considerações por parte de trabalhos que indicam a necessidade de que a epidemiologia se aproxime das categorias nativas de distintividade, no sentido de qualificar a descrição dos eventos de saúde/doença.

As categorias de idade empregadas nos censos e registros de morte ou suicídios entre os Tikúna seguem o modelo de classificação do dado bruto em classes de periodização constante $(<1,1,2,3,4,5-9,10-14$, etc.) ou, mesmo, recortes ainda mais amplos $(<1,1-4,5-14,15-$ 58 etc.), que não refletem os recortes específicos através dos quais as populações estudadas classificam seus indivíduos. 
Para o estudo do suicídio Tikúna será de grande valia, levando em conta essas observações, buscar o entendimento das categorias de idade através das quais os indivíduos são classificados. A Tabela 2, elaborada originalmente com o objetivo de nortear as discussões acerca dos papéis exercidos pelos diferentes atores no cenário político Tikúna, pode ser tomada como base para a elaboração de outros recortes de categorias de idade que permitam vislumbrar conteúdos mais específicos para os diferentes períodos da vida dos Tikúna.

A Tabela 3 apresenta todos os suicídios anotados de 1990 a 1997, divididos por idade e sexo, agora separados em categorias de idade pensadas com base nos critérios Tikúna de classificação.

A referência de Oliveira Filho (1988) ao período em torno dos 18 anos como sendo aquele em que, via de regra, os rapazes já estão casados e com dois filhos, permitiu estabelecer o período em torno dos 16 anos como o momento provável de ocorrência da maioria dos casamentos para os rapazes. Esse dado foi corroborado pelos jovens entrevistados em Belém do Solimões. A faixa etária entre 12-15 anos indica, para as meninas, o período provável de ocorrência da primeira menstruação, quando elas devem passar pelo ritual da Moça Nova (Nimuendajú, 1952), que as torna aptas ao casamento. Apesar de o período de reclusão envolver grande quantidade de ansiedade e expectativa em relação ao aprendizado de como ser "boa esposa" e continuar sendo "boa filha", o ritual de passagem assegura o "casamento certo". Apesar da intolerância religiosa e/ou dos processos violentos de contato terem impedido a realização do ritual da "Moça Nova”, a obediência às regras de casamento não é colocada em discussão. Os meninos são extrema- mente sensíveis nessa faixa de idade em que mudam de voz e alguns acabam por entrar em contato com os encantados (ü̈̈ne) ou com diversos tipos de demônios ( $n^{\prime} g o$ ), podendo vir a tornar-se pajés ou intermediários de mensagens salvacionistas. Essa faixa de idade contribuiu com 9.1\% dos suicídios, não havendo ocorrência entre menores de 12 anos.

No grupo de 16-18 anos ocorreram $47,2 \%$ do total dos suicídios registrados, com preponderância de indivíduos do sexo masculino. Em relação ao meio utilizado, todos os que ingeriram timbó eram do sexo masculino, mas a forca foi preferencialmente utilizada por $65,3 \%$ dos indivíduos desse grupo, inclusive as 2 únicas mulheres. Esse período parece ser aquele em que o jovem enfrenta as situações de maior conflito e mudanças. O casamento marca o início de nova fase, e o costume do bride-service obriga o deslocamento do rapaz para a casa do sogro (nação oposta), onde ocupará novo lugar

Tabela 1

Suicídio Ticuna por Ano e Sexo.

\begin{tabular}{lccc}
\hline & Masculino & Feminino & Total \\
\hline 1990 & 1 & 0 & 1 \\
1991 & 2 & 2 & 4 \\
1992 & 1 & 0 & 1 \\
1993 & 6 & 3 & 9 \\
1994 & 9 & 4 & 13 \\
1995 & 3 & 3 & 6 \\
1996 & 11 & 1 & 12 \\
1997 & 9 & 2 & 11 \\
Total & 42 & 15 & 57
\end{tabular}

Tabela 2

Categorias de idade e seus conteúdos.

\begin{tabular}{|c|c|c|c|c|c|c|}
\hline & Sexo & $0-12$ & $12-18$ & $18-25$ & $25-60$ & +60 \\
\hline \multirow[t]{2}{*}{ Termo Traduz. } & M & Criança & "rapaz" & "homem" & "velho" & "vovô" \\
\hline & $\mathrm{F}$ & & "moça" & "mulher" & "velha" & "vovó" \\
\hline \multirow[t]{2}{*}{ Termo Nativo } & M & Pakobê & Pakê & Mareãmakê & Djaguanta & oí \\
\hline & $\mathrm{F}$ & lakobê & Ngeutákê & Mareatakê & Djakêdjê & noé \\
\hline Conteúdo categoria & & "até formar" & $\begin{array}{l}\text { casado } \\
\text { ou solteiro }\end{array}$ & $\begin{array}{l}\text { Casado até } \\
3 \text { filhos }\end{array}$ & $\begin{array}{l}\text { casado }+ \\
\text { de } 3 \text { filhos }\end{array}$ & $\begin{array}{l}\text { Todos os } \\
\text { anciãos }\end{array}$ \\
\hline
\end{tabular}

Fonte: Oliveira Filho, 1977. 
Tabela 3

Distribuição dos suicídios por faixa etária e sexo na população Ticuna - 1990/1997.

Municípios cobertos pela Delegacia Regional da FUNAI/Tabatinga e FNS/SESAU/Tabatinga.

\begin{tabular}{lrrrrrr}
\hline \multirow{2}{*}{ Idade (anos) } & \multicolumn{3}{c}{ No. de Suicídios } & \multicolumn{3}{c}{ Suicídios (\%) } \\
& $M$ & $F$ & Total & M & $F$ & Total \\
\hline $00-11$ & - & - & - & - & - & - \\
$12-15$ & 3 & 2 & 5 & 5.5 & 3.6 & 9.1 \\
$16-18$ & 24 & 2 & 26 & 43.6 & 3.6 & 47.2 \\
$19-25$ & 10 & 5 & 15 & 18.2 & 9.1 & 27.3 \\
$26-60$ & 4 & 2 & 6 & 7.3 & 3.6 & 10.9 \\
$60-\ldots$ & - & 3 & 3 & - & 5.5 & 5.5 \\
Total & 41 & 14 & 55 & 74.6 & 25.4 & 100 \\
\hline
\end{tabular}

social, próximo ao lugar de filho, mas, ao mesmo tempo, diferente deste papel, já que dentro de uma unidade diversa e em posição de submissão à autoridade do sogro.

Se, no presente, a divisão da sociedade Tikúna em nações cumpre o papel de regulamentar o casamento, no passado, cada nação estava agrupada em grandes malocas que pressupunham certo território e se constituíam como unidades políticas independentes e soberanas. Os Tikúna formavam então uma sociedade de tipo segmentar (acéfala), em que a unidade tribal seria resultado das trocas matrimoniais, do uso da mesma língua e do fato de compartilharem a mesma tradição cultural. As relações entre as nações eram marcadas por tensão, que levava, com freqüência, a acusações de atos de feitiçaria e, daí, a choques armados e a atos de guerra que poderiam culminar com a eliminação ou afastamento de um dos grupos. O fato de as relações entre as malocas se constituírem através das trocas matrimoniais, concorria para atenuar a hostilidade latente entre essas unidades.

A dissolução da maloca clânica realizada pelos "patrões" seringalistas marcou também o término das guerras entre as nações, com a conseqüente perda da unidade tribal, proporcionada por esse relacionamento guerreiro e trocas matrimoniais. Na mesma unidade (aldeia), passaram a coexistir indivíduos de nações opostas o que permitiu a realização de casamentos no interior da mesma.

A multiplicação de pajés, curadores e feiticeiros pode corresponder a uma situação de busca da unidade do grupo construída em outras bases, não mais como antes, a partir das relações entre grupos clânicos (nações) localizados, mas em função de diversas conjunturas no que se refere às possibilidades de negociações entre "grupos locais de famílias inter-relacionadas" (Nimuendajú, 1952; Oliveira, 1996; Oliveira Filho, 1977) ou entre comunidades, em função de objetivos políticos diferenciais.

Principalmente, os jovens do sexo masculino em foco encontram-se, nos dias de hoje, em momento extremamente importante em termos de decisões e/ou posições, a serem assumidas: a continuidade ou não dos estudos, a busca de opções de trabalho remunerado dentro e fora das aldeias, o alistamento no serviço militar, o engajamento nas estruturas de formação de lideranças religiosas ou políticas, o casamento, o trabalho na roça e na pesca de subsistência, a pesca do peixe de couro para venda; algumas dessas opções vêm-se realizando de forma conjugada e podendo expressar níveis diferenciados de alianças políticas. Obviamente que essas escolhas passam, tanto na sua definição quanto nas suas possibilidades de realização, pelo pertencimento aos diferentes grupos de poder e da posição relativa desses grupos em cada conjuntura.

Entre 19-25 anos, o agora jovem adulto, casado, certamente já se definiu em termos de sua escolha ocupacional e tem a responsabilidade de sustentar a família. Essa faixa etária contribuiu com $27,3 \%$ do total de suicídios e é, da mesma forma, majoritariamente composta por indivíduos do sexo masculino (Tabela 3). Este é um momento em que os jovens adultos passam a expressar-se de forma mais ativa, podendo assumir posições contrárias aos interesses de outras coortes de idade. Os relatos dos eventos nessa faixa etária enfatizam duas situações que parecem complementares: a presença acentuada de usuários de bebida alcoólica e a grande instabilidade do casamento que ocasiona, por sua vez, violência intensa dentro da unidade familiar.

É importante anotar que o suicídio atribuído a ato de enfeitiçamento pode atingir não somente os mais jovens, que são os mais vulneráveis, mas também aqueles que, tendo acumulado alguns bens ou conseguido condição de vida melhor do que o conjunto da comunidade, passam a atrair a "inveja" dos outros. O feitiço, aqui, parece funcionar como mecanismo informal de controle social, uma vez que o feiticeiro capta, em alguns momentos, a insatisfação de grupos opostos.

Entre os 26-60 anos, o homem é considerado "experiente" e suas posições têm peso diferencial dentro da família nuclear e em relação ao grupo vicinal. Ainda a partir da Tabela 3 observa-se que a freqüência de suicídio dessa faixa etária é o segundo mais baixo (10,9\%), com 
concentração de suicídios em seu limite inferior, podendo mostrar a necessidade de futuro desdobramento deste recorte. Apesar da menor incidência de suicídios entre o segmento feminino $(23,6 \%)$, o perfil da mulher Tikúna parece estar passando por um processo de reformulação, o que pode ocasionar mudança de padrão do evento para esta população.

Tomada a questão da possibilidade de vinculação entre o suposto aumento de suicídio e maior presença do uso do álcool nas comunidades Tikúna onde ocorre maior incidência de casos, o uso de bebidas alcoólicas deve ser avaliado dentro de marcos mais gerais de entendimento dos significados diversos que esse uso pode assumir em sociedades indígenas. O uso das bebidas fermentadas é tradicional entre os Tikúna. Vários autores, no entanto, já citaram a mudança significativa de comportamento dos Tikúna ao beber. Um quadro de intoxicação pela bebida parece sancionar, em determinados contextos, a ocorrência de discussões e acusações, as quais podem desdobrar-se em brigas que resultam em ferimentos ou mortes. Tanto as festas rituais quanto as festas de fim de semana podem ser o cenário ideal para a concretização de discussões, brigas e vinganças que seriam inadmissíveis dentro de situação cotidiana. Nimuendajú (1952) cita as festas de celebração e as reuniões de trabalho como os momentos de ocorrência da quase maioria dos crimes de morte. A ingestão de grandes quantidades de bebida faria aflorar uma intensa disponibilidade nos índios para discussões violentas, onde são insultados os próprios parentes, com desdobramentos constantes em mortes. Ainda se refere especialmente à ocorrência dessas discussões entre cunhados, levantando a questão em torno da grande tensão existente entre elementos de distintos clãs que, por força do casamento, passariam a conviver por período mais ou menos longo em uma mesma unidade familiar.

Portanto, as observações acerca do aumento do consumo excessivo de álcool nas comunidades de Umariaçú ou Belém do Solimões podem estar indicando menos a existência de indivíduos portadores de patologia, ou com problemas de adaptação, do que a existência de conjunturas econômicas e sociais desfavoráveis, dando margem ao surgimento de momentos de grande tensão entre grupos vicinais, entrecortados também pelos faccionalismos políticos e religiosos, certamente espelhando a total ausência de propostas conseqüentes e investimentos governamentais, principalmente no que diz respeito à saúde, ao controle das terras e de seu patrimônio ambiental.

\section{Uma explicação nativa para o suicídio}

O suicídio em sociedades indígenas tem sido associado a processos de inadaptação de indivíduos ou grupos às exigências externas de desenvolvimento e/ou processos de integração na sociedade nacional com a qual entram em contato.

A pesquisa feita entre os Tikúna permitiu a reavaliação dos discursos relativos ao suicídio indígena advindos de diversos agentes/agências do contato, cada qual disputando a legitimidade de seus projetos junto à população. A possibilidade da "autoria" de modos diferenciados de relações com vários atores vai estar, no entanto, intensamente marcada e limitada por situação de choque de interesses e ideologias desses mesmos atores, em que prevalece o poder de determinada força social.

A explicação recorrente dos suicídios como oriunda de conflitos familiares, fruto da desobediência ao padrão tradicional de casamento foi registrada em apenas dois casos, o que parece estar dentro de expectativa razoável de ocorrência de casamentos incestuosos. Nos casos em que houve relações incestuosas, o suicídio pôde ser acionado como solução restauradora de situação de equilíbrio, na qual são preservados os princípios básicos inscritos no mito de criação que definem a sociedade Tikúna. O trabalho de campo e os relatos recolhidos permitem indicar o ato do suicídio como resposta a determinadas situações de conflito informadas por padrões culturais de relacionamento intrafamiliar, que têm sido interpretadas como "problemas de nação".

Na verdade, a recusa dos pais no tocante às escolhas matrimoniais dos filhos e, principalmente, em relação ao parceiro da filha parece estar centrada na questão da possibilidade de o rapaz sustentar a família, o que é definido segundo os padrões tradicionais: saber pescar, fazer roça grande, ter habilidade para fazer canoa. A desqualificação do indivíduo envolvida na recusa de um pedido de casamento, pode estar de modo mais contundente na base do ato do suicídio do que propriamente a "perda da amada" ou, ainda, a explicação do "problema de nação".

Em outro tipo de situação de suicídio, identifica-se mudança brusca de comportamento dos rapazes de boa índole e bom rendimento escolar a partir de uma reprimenda dos pais "ficam com muita raiva" -, passando a comportar-se de forma "fora do normal". A "perda da razão" parece estar associada à ingestão de grande quantidade de bebidas alcoólicas e a comportamentos que afetam diretamente os 
familiares, trazendo vergonha para todos. No caso específico de famílias pertencentes à Igreja da Cruz - movimento messiânico surgido na década de 70, que exige o total abandono dos rituais tradicionais, feitiçaria, bebidas, músicas -, as atitudes dos filhos tidas como impróprias pela Igreja devem ser purgadas pelos pais. Alguns relatos confirmam a norma da Igreja de expulsão temporária dos pais, quando "o pai paga pelo filho", sua volta ficando condicionada à confissão pública do pecado.

O tema da "raiva", que surge associado a eventos banais, parece vinculado ao fato de as reprimendas dirigidas ao indivíduo partirem de elementos da família em relação aos quais este se encontre em posição de submissão. Os eventos banais que desencadeiam a atitude suicida parecem estar na superfície de longos períodos de tensão, indicando a valorização das relações familiares. Neste sentido, o álcool serve como "instrumento liberador" de sentimentos negativos que não devem ser expressos, em especial, em relação às pessoas com as quais se tenha relação de respeito e amor.

Da mesma forma que para a sociedade Trukese da Micronésia, na qual os eventos de suicídio - respostas impulsivas a situações triviais - são qualificados como fruto de personalidades instáveis, a proposta é que se interprete as explicações nativas como "textos" culturalmente construídos, que expressam noções e valores centrais a determinada cultura (Hezel, 1984). No caso Tikúna, é possível levantar a hipótese de que o suicídio seja interpretado não somente como ato de agressão dirigido ao próprio indivíduo, mas, da mesma forma, como ato de expressão da raiva contra os parentes próximos. Uma parte da alma (nacii') permanece no lugar onde o indivíduo morre, podendo ocasionar infortúnios ou mesmo a morte daqueles que com ela entrem em contato.

Os suicídios podem ser ocasionados pela "vingança” que, em geral, tem a sua origem em agressão física anterior ou apenas em brigas e discussões - entre familiares - por motivos aparentemente banais. Os conflitos intergeracionais e intrafamiliares podem ter a sua explicação colocada em elemento externo e mágico - feitiço -, retirando do âmbito das relações familiares a responsabilidade pelo ato de um dos seus componentes.

Outro tema que, de forma importante, emerge igualmente dos relatos, diz respeito à questão da "inveja”, desencadeadora de longos processos de disputas, que podem se concretizar através das ocorrências de doenças, mortes violentas e/ou suicídios. A identificação de um indivíduo ou de determinado grupo com o con- trole de poder político exacerbado, a posse de bens materiais, a mudança de status econômico, a ocupação de cargos assalariados ou que impliquem acesso a ganhos monetários tendem a desencadear a expressão de insatisfações pela atitude "suvina" de alguém.

O exercício de destacar os temas principais de cada conjunto de casos conhecidos (Erthal, 1998) não tem por objetivo explicitar uma tipologia do suicídio Tikúna a partir da qual seja possível inferir categorias generalizantes e deve ser visto dentro de limites, na medida em que tais casos podem ser reconhecidos como coadjuvantes uns dos outros em cada situação. A conjunção dos vários temas é elaborada apenas através do modelo etiológico Tikúna, que interpreta determinada conjuntura histórica com fundamento nos nexos particulares colocados pela cultura e organização social. Para entender essa 'fala' é preciso buscar as bases nas quais a mesma está construída.

Os mitos Tikúna descrevem acontecimentos no passado que devem explicar os costumes e as crenças atualizadas no tempo presente. A história do jovem Metare fala do homem que "comia" todos os rapazes para os quais oferecia sua filha. Um dia, Metare resolveu acabar com isso, senão "aquele que chupa" poderia destruir todo o povo: "Ele vai nos destruir!” (Nimuendajú, 1952:145). Uma versão desse mito recolhida mais recentemente conta que Metare casou com a filha de um homem que era "bicho" e matava todos os genros para "comer". Chamava o genro para comer beiju, mas antes mandava que subisse na palmeira de bacaba com uma corda enrolada no pescoço. Quando o genro chegava no alto, puxava a corda. Assim, ele matou cinco genros. Quando chegou a vez de Metare, ordenou que a filha fizesse pamonha e o chamou para pegar bacaba no mato. Mandou que fosse tirar cipó no outro lado, pois ali tinha formigas de fogo. Metare enganou o sogro, foi ao lado proibido e viu os ossos dos outro genros que Witchicü tinha comido. Quando voltou, o sogro mandou que prendesse o cipó no pescoço e subisse para pegar a fruta. $M e$ tare colocou o cipó nos ombros e o sogro mandou novamente que o pusesse no pescoço. Então, Metare transformou-se em japó e Witchicü viu que tinha perdido sua comida. O pássaro cantou e Witchicü, sem perceber, comeu a carne da própria perna. O japó cantou de novo e o sogro comeu a outra perna, e assim por diante. No fim só restaram os ossos, a cabeça e o coração, mas ainda estava vivo. Aí, o japó queimou Witchicü e acabou tudo (Índios Tikúna, 1985).

Esse mito parece deixar evidente a posição de instabilidade do jovem recém-casado den- 
tro da casa do sogro, onde está fraco e pode ser morto pela feitiçaria. Os rapazes são mortos por enforcamento e apenas Metare, que havia sido tratado por sua mãe com um remédio que o tornara imortal e o fizera crescer um rapaz prudente e sensato, consegue salvar o povo de tantas mortes.

Do mesmo modo que as almas (nacii'), os demônios também podem "chupar o sangue" e "comer" aqueles que andam pela floresta nas horas perigosas ou que se assustam com os seus barulhos no meio da noite. Os suicídios são atribuídos igualmente a feitiço, acionado a partir do espírito mau que o pajé manda para atormentar seu inimigo. O pajé possui 3 espíritos maus: matintin (matita), mui mui, tchatchacuna. Então, os suicídios seriam o resultado de enfeitiçamento específico, que mobiliza um dos espíritos maus do pajé, o tchatchacuna. Este espírito, ao colocar-se ao lado, abraçado ao indivíduo, faz com que mude de atitude, passando a ter comportamento anti-social, de desobediência e desacato aos pais. O comportamento do indivíduo sob a interferência desse espírito é associado ao comportamento de alguém que "enlouquece" e perde a consciência do que faz.

O feitiço do "tchatchacuna" não fica restrito a uma só pessoa, podendo atingir vários membros de um grupo familiar. O encadeamento de suicídios na mesma família nuclear ou que tem relações de afinidade e consangüinidade é explicado pelo feitiço do "tchatchacuna”. Para a ocorrência de suicídios na área do Alto Solimões - que são encadeados dentro do mesmo núcleo familiar e em curto espaço de tempo - pode-se mapear um modelo mais complexo do que aquele apontado pelo efeito de "familiaridade" e/ou "contágio" (CDC, 1988, 1994), quando referenciado a situações datadas historicamente, nas quais os atores são capazes de formular projetos políticos - muitas vezes, distintos e divergentes -, fazer e desfazer alianças, "comendo o inimigo" até que ele "se acabe".

Assim, o feitiço do tchatchacuna parece condensar os diferentes níveis de explicitação dos conflitos em sociedade marcada pelo intenso faccionalismo, podendo explicar tanto os sintomas de comportamento disruptivo e perda de consciência (comportamento agressivo, desrespeito aos pais, bebedeiras etc.) quanto a causa última da morte, designando o agressor, dando sentido ao evento e abrindo a possibilidade ou de continuidade do conflito, ou de acordo entre as partes.

A sucessão de suicídios que ocorreu a partir de 1990 pôde, desse modo, ser relacionada não em termos das aproximações religiosas, encadeamentos geográficos e temporais que são mais evidentes, mas como possível descritor de momento específico do processo concreto de interação social e das percepções que os diferentes grupos faccionais têm dele. Faz sentido, então, vincular os suicídios ocorridos nas comunidades do igarapé do Belém com a ação dos pajés de Vendaval, com as invasões de lagos de preservação de peixes, com as "vinganças" e perseguições a pajés que têm seu desenlace fatal em Umariaçú e assim por diante, definindo a 'situação' como o conjunto das relações entre atores sociais. A história do tchatchacuna, pode ser entendida como recurso explicativo que parece dar sentido e alinhavar as diferentes formas de atualização de conflitos.

Correndo o risco de fazer inferências para além das possibilidades das informações recolhidas, não parece totalmente descartável a viabilidade de interligar os eventos de suicídio e violência da década de 90 com a exacerbação dos conflitos criados pela invasão das áreas consideradas de controle de outras comunidades e, na verdade, patrimônio e reserva de riqueza das mesmas (lagos de preservação), fruto de escolhas divergentes de formas de apropriação dessas riquezas - exploração pelas comunidades X e comercialização do pescado com representantes de frigoríficos colombianos. Neste contexto, as comunidades - ou, mais especificamente, seus grupos vicinais realizam, em outro contexto histórico, os mecanismos de resolução de conflitos próprios das antigas malocas, que podem ser percebidos através dos eventos de doença, violência e morte imputados aos diversos grupos em confronto.

\section{Considerações finais}

Para a população Tikúna, as conseqüências do confronto contínuo entre FUNAI e FNS pelo controle da saúde indígena no Alto Solimões a partir do início da década de 90 fizeram-se sentir também na ausência de coleta sistemática e normatizada dos dados de morbimortalidade e, ainda, na destruição das fichas de atendimento encontradas nos postos de saúde anteriormente gerenciados pela FUNAI (Erthal, 1996).

Vários autores têm chamado a atenção para a questão do sub-registro de mortes violentas e, em especial, para as mortes por suicídio nas sociedades urbanas e indígenas (Barros, 1991; Cassorla, 1991; Minayo, 1994). A ausência de registros sistemáticos dos casos de suicídio entre os Tikúna que foram anteriores à década 
de 90, impossibilita o estabelecimento de quaisquer parâmetros de comparação que permitam a afirmação da ocorrência de "aumento" ou de taxas "anormais" de suicídio na área. Mais que isso, todas as circunstâncias de maior presença de profissionais de saúde na área, a partir de 1991 - com a chegada do cólera ao Alto Solimões (Programa de Agentes Comunitários de Saúde/Ministério da Saúde, FNS, FUNAI, Universidade Federal do Rio de Janeiro, Médicos sem Fronteira, Fundação Oswaldo Cruz), as mudanças na constituição do modelo assistencial, e um foco importante dado às notificações de óbito na formação de agentes indígenas de saúde - podem estar indicando não a existência de epidemia de suicídios, mas sim a maior notificação de casos. A constatação posterior de estabilidade das taxas de suicídio principalmente para o período de 1993/1997 (Tabela 1) - parece indicar, da mesma forma, a impropriedade da tese de epidemia.

A caracterização de um modelo de suicídio para as sociedades indígenas tem-se pautado, de modo geral, pela necessidade de identificação dos "grupo(s) de risco" para os quais se pretende elaborar "programas de intervenção". A elaboração de categorias de "indivíduos de risco" para o suicídio por uma epidemiologia clássica pode levar à constituição de tipologias construídas apenas através de características factíveis de comparação e medição, não necessariamente refletindo a complexidade e a diversidade da ocorrência do evento. A contribuição que a antropologia tem colocado aos estudos epidemiológicos vai mais além do que apenas algumas críticas aos abusos da quantificação. A antropologia tem-se negado a tratar indivíduos como "casos" desencarnados de toda a vida social e procurado ver, por trás de seus informantes, indivíduos social e culturalmente determinados.

A concentração de casos de suicídio nas faixas etárias de 16-18 anos (47,2\%) e 19-25 anos $(27,3 \%)$ parece indicar o alto grau de instabilidade vivido por estes jovens adultos - em particular, os do sexo masculino - dentro de sociedade altamente marcada por divisões faccionais e pela importância das relações familiares.

Assim, para a continuidade das discussões a respeito do suicídio indígena interessa chamar a atenção para o fato de que este deve ser visto como modelo culturalmente desenhado para responder a determinadas situações de conflito. Os dados que foram acumulados no decorrer da pesquisa proporcionam a moldura necessária ao entendimento dos diferentes conteúdos que o evento do suicídio pode assumir, sem que os mesmos percam seu caráter reafirmador de uma visão particular de mundo, que caracteriza e define o povo Tikúna.

Finalmente - e de forma incisiva -, a constatação de vinculação moldada culturalmente entre os eventos de doença e de violência deve fazer refletir acerca da possibilidade de intervenção não em "indivíduos de risco", mas através de programas indiretos, desenhados para trabalhar com os fatores intervenientes na constituição das taxas de adoecimento, infortúnios e violências em geral. Isto é, ao abandono, à pobreza, à ausência de saneamento básico e de assistência à saúde, à degradação ambiental, à escassez alimentar e à invasão do território deve-se fazer corresponder projetos de desenvolvimento sustentado e, principalmente, projetos de saúde realmente desenhados para populações culturalmente diferenciadas.

\section{Agradecimentos}

A autora agradece ao AIS Tertulino Mendes, que serviu como intérprete nas buscas constantes por informantes qualificados. 


\section{Referências}

BARROS, M. B. A., 1991. "As Mortes por suicídio no Brasil”. In: Do suicídio: Estudos brasileiros (Roosevelt M. S. Cassorla, org.), pp. 41-53, Campinas: Papirus.

BARTH, F., 1967. On the Study of Social Change. American Anthropologist, 69:661-669.

CASSORLA, R. M. S. (org.), 1991. Do suicídio: Estudos brasileiros. Campinas: Papirus.

CDC (Centers for Disease Control and Prevention), 1988. Cluster of Suicide and Suicide Attempts New Jersey. MMWR, 37:213-216.

CDC (Centers for Disease Control and Prevention),, 1994. Suicide contagion and reporting of suicide: Recommendations from a National Workshop. MMWR, 45:13-17.

CHAUMEIL J. P., 1986. Nihamwo. Los Yagua del NorOriente Peruano. Lima: Centro Amazónico de Antropología y Aplicación Práctica.

ERTHAL, R. M. C., 1996. O Suicídio Tikúna: uma tentativa de aproximação. In: XXa Reunião Brasileira de Antropologia e I Conferência: Relações Étnicas e Raciais na América Latina e Caribe, 14 a 18 de abril de 1996. Salvador: Associação Brasileira de Antropologia.

ERTHAL, R. M. C., 1998. O Suicídio Tikúna na Região do Alto Solimões - AM. Tese de Doutorado, Rio de Janeiro: Escola Nacional de Saúde Pública, Fundação Oswaldo Cruz.

ERTHAL, R. M. C; CONFALONIERI, U. E. C. \& HOKERBERG, Y. H. M., 1994. The Alto Solimões Region. In: Amazon Health Report. Indigenous Peoples of Brazil (U. E. C. Confalonieri, org.), part III. pp. 76103, Rio de Janeiro: Médicos pelo Ambiente (MEPA)/World Bank, October.

GLUCKMAN, M., 1968. Analysis of a social situation in modern zululand [1939]. The Rhodes-Livigstone Papers, 28. Manchester: Manchester University Press.

GOLDBERG, M., 1990. Este obscuro objeto da Epidemiologia. In: Saúde em Debate Epidemiologia. Teoria e Objeto (D. C. Costa, org.), pp. 87-136, São Paulo: Editora Hucitec/Rio de Janeiro: ABRASCO.

HEZEL, F. X., 1984. Cultural patterns in Trukese suicide. Ethnology, 23:193-206.

ÍNDIOS TIKÚNA, 1985. Torü duü'ü, ü ügü (nosso povo). Rio de Janeiro: Museu Nacional/SEC/Ministério de Educação e Cultura/Memórias Futuras Edições.
ISA (Instituto Socioambiental), 1996. Lista de Povos Indígenas no Brasil Contemporâneo. In: Povos Indígenas no Brasil: 1991-1995 (C. A. Ricardo, ed.), pp. 6-11, São Paulo: Instituto Socioambiental.

LANGDON, E. J. M., 1994. Representações da doença e Itinerário Terapêutico dos Siona da Amazônia Colombiana. In: Saúde e Povos Indígenas (R. Santos \& C. E. A. Coimbra Jr., org.), pp. 115-141, Rio de Janeiro: Editora Fiocruz.

MACEDO, G. M., 1996. Negociando a identidade com os brancos: religião e política em um núcleo urbano Tikúna. Dissertação de Mestrado, Rio de Janeiro: Programa de Pós-Graduação em Antropologia Social, Museu Nacional, Universidade Federal do Rio de Janeiro.

MINAYO, M. C. S., 1994. A violência social sob a perspectiva da saúde pública. Cadernos de Saúde Pública, 10:07-18.

NIMUENDAJU, C., 1952. The Tukúna. Berkeley and Los Angeles: University of California Press.

OLIVEIRA, R. C., 1978.Possibilidade de uma antropologia da ação (1975). In: A Sociologia do Brasil Indigena. pp. 197-221. Rio de Janeiro: Tempo Brasileiro/Brasília: Editora da UnB.

OLIVEIRA, R. C., 1996. O índio e o mundo dos brancos. 4ed. (1.ed.1961). Campinas: Editora UNICAMP.

OLIVEIRA FILHO, J. P., 1977. As facções e a ordem política em uma reserva Tukuna. Dissertação de Mestrado, Brasília: Faculdade de Antropologia Social, FUnB.

OLIVEIRA FILHO, J. P., 1988. "O Nosso Governo": Os Tikúna e o regime tutelar. São Paulo/Brasília: Marco Zero/MCT/CNPq.

TAUSSIG, M., 1993. Xamanismo, colonialismo e o homem selvagem. Um estudo sobre o terror e a cura. São Paulo: Editora Paz e Terra.

VERANI, C. B. L., 1996. Anteprojeto de implantação de um Sistema Unificado de Informação e Vigilância Epidemiológica, específico para a saúde do índio: Organização, avaliação, elaboração de indicadores específicos de saúde e antropológicos, reestruturação e treinamento de pessoal. (mimeo.)

WACHTEL, N., 1976. Los vencidos: los indios del Perú frente a la conquista española (1530-1570). Madrid: Alianza.

YOUNG, A., 1982 - The anthropologies of illness and sickness. Annual Review of Anthropology, 11:25785. 